SUPPORTED COMPLEX AND HIGH RISK CORONARY ANGIOPLASTY 


\section{INTERVENTIONAL CARDIOLOGY}

AMAR S. KAPOOR, SERIES EDITOR

Shawl, F.A., ed.: Supported Complex and High Risk Coronary Angioplasty, 1991. ISBN 0-7923-1121-3. 


\title{
SUPPORTED COMPLEX AND HIGH RISK CORONARY ANGIOPLASTY
}

\author{
EDITED BY FAYAZ A. SHAWL, M.D., FACC
}

Director, Interventional Cardiology

Washington Adventist Hospital, Takoma Park, Maryland

Clinical Associate Professor of Medicine (Cardiology)

George Washington University School of Medicine, Washington, D.C.

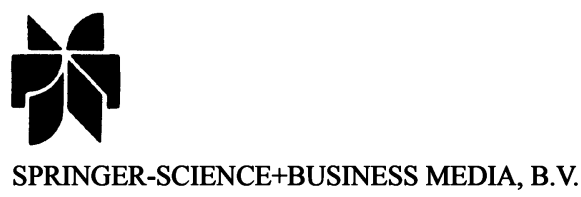




\section{Library of Congress Cataloging-in-Publication Data}

Supported complex and high risk coronary angloplasty/Fayaz A. Shawl (editor).

p. $\quad \mathrm{cm} .-$ (Interventional cardiology; INCA 001)

Includes index.

ISBN 978-1-4613-6735-2

ISBN 978-1-4615-3890-5 (eBook)

DOI 10.1007/978-1-4615-3890-5

1. Transluminal angioplasty. 2. Cardiopulmonary bypass.

3. Therapeutics, Surgical. I. Shawl, Fayaz A. II. Series.

[DNLM: 1. Angioplasty, Transluminal, Percutaneous Coronary.

2. Cardiopulmonary Bypass. 3. Coronary Disease - therapy. 4. Risk Factors. WG 300 S959]

RD598.S836 1991

$617.4^{\prime} 12059-\mathrm{dc} 20$

DNLM/DLC

for Library of Congress

\section{Copyright (ㄷ 1991 Springer Science+Business Media Dordrecht}

Originally published by Kluwer Academic Publishers in 1991

\section{Softcover reprint of the hardcover 1st edition 1991}

All rights rescrved. No part of this publication may be reproduced, stored in a retricval system or transmitted in any form or by any means, mechanical, photocopying, recording, or otherwise, without the prior written permission of the publisher, Springer-Science+Business Media, B.V. 


\section{DEDICATION}

I would like to dedicate this book to the memory of my late father, Mohammad Salcem Shawl. 


\section{CONTENTS}

Contributing authors $\quad$ ix

Acknowledgments xiii

Foreword $\quad$ xv

Preface xvii

\section{SECTION I.}

1. Identification of the High-Risk Angioplasty Patient 3 STEPHEN G. ELLIS

2. Myocardial Protection During Coronary Angioplasty 21 DANIEL WOHLGELERNTER

\section{SECTION II.}

3. Extracorporeal Cardiopulmonary Bypass Support: A Historical and Current Perspective

A. KENNETH LIRZIE

4. Basic Principles of Cardiopulmonary Bypass GEORGE A. JUSTISON

5. Echocardiographic and Hemodynamic Changes During Percutaneous Cardiopulmonary Bypass Support

JAMES A. RONAN, JR., FAYAZ A. SHAWL, M.D.

6. Percutaneous Cardiopulmonary Bypass Support: Technique, Indications, and Complications

FAYAZ A. SHAWL 
7. Percutaneous Cardiopulmonary Bypass Support in Patients Undergoing "High-Risk" Coronary Angioplasty FAYAZ A. SHAWL

8. Emergency Institution of Cardiopulmonary Bypass Support In Cardiogenic Shock MICHAEL J. DOMANSKI, FAYAZ A. SHAWL

9. Emergency Percutaneous Cardiopulmonary Bypass Support in Patients with Cardiac Arrest FAYAZ A. SHAWI

10. Decision Making During Femoro-Femoral Veno-Arterial Cardiopulmonary Bypass Support in the Cardiac Catheterization Laboratory

A. KENNETH LITZIE

\section{SECTION III.}

11. Intraaortic Balloon Pump Supported High-Risk Coronary Angioplasty MARC H. WISH, FAYAZ A. SHAWL

12. Myocardial Protection During Coronary Angioplasty Using Autoperfusion Catheters ALAN N. TENAGLIA, E. MAGNUS OHMAN, RICHARD S. STACK

13. Synchronized Coronary Venous Retroperfusion During Coronary Angioplasty SHEILA KAR, ALICE K. JACOBS, DAVID P. FAXON

14. Clinical Experience with the hemopump Left Ventricular Assist Device RICHARD K. WAMPLER, RAYMOND A. RIEHLE 


\section{CONTRIBUTING AUTHORS}

Michael J. Domanski, M.D., F.A.C.C.

Senior Staff Cardiologist

National Heart Lung and Blood Institute

National Institutes of Health

Clinical Assistant Professor of Medicine

U.S.U. School of Medicine

Bethesda, MD 20892

Stephen G. Ellis, M.D., F.A.C.C.

Assistant Professor of Medicine

Assistant Director, Cardiac Catheterization Laboratory

The University of Michigan Medical Center

Ann Arbor, MI 48109-0022

David P. Faxon, M.D., F.A.C.C.

Director, Division of Cardiology

Boston University Medical Center

Boston, MA 02118

Alice K. Jacobs, M.D., F.A.C.C.

Director, Cardiac Catheterization Laboratory

Section of Cardiology

Boston University Medical Center

Boston, MA 02118 
George A. Justison, B.S., C.C.P.

Chief Perfusionist

William Beaumont Hospital

Royal Oak, MI 48072

Sheila Kar, M.D., F.A.C.C.

Research Scientist

Division of Cardiology

Department of Medicine

Cedar Sinai Medical Center

Los Angeles, CA 90048

A. Kenneth Litzie, B.A., C.P.

Director, Mechanical Assist Division

PSICOR, Inc.

San Diego, CA 92127

E. Magnus Ohman, M.D.

Coordinator of Clinical Trials

Interventional Cardiology

Duke University Medical Center

Durham, NC 27710

Raymond A. Riehle

Clinical Trials Coordinator

Nimbus, Incorporated

Rancho Cordova, CA 95670

James A. Ronan J., M.D., F.A.C.C.

Clinical Professor of Medicine (Cardiology)

Georgetown University School of Medicine

Co-Director, Department of Cardiology

Washington Adventist Hospital

Takoma Park, MD 20912

Fayaz A. Shawl, M.D., F.A.C.C.

Clinical Associate Professor of Medicine (Cardiology)

George Washington University School of Medicine

Director, Interventional Cardiology

Washington Adventist Hospital

Takoma Park, MD 20912 
Richard S. Stack, M.D., F.A.C.C.

Associate Professor of Medicine (Cardiology)

Director, Interventional Cardiology Program

Duke University Medical Center

Durham, NC 27710

Alan N. Tenaglia, M.D.

Cardiology Fellow

Duke University Medical Center

Durham, NC 27710

Richard K. Wampler, M.D., F.A.C.C.

Director, Medical Affairs

Nimbus Incorporated

Rancho Cordova, CA 95670

Marc H. Wish, M.D., F.A.C.C.

Assistant Clinical Professor of Medicine

Georgetown School of Medicine

Staff Cardiologist

Prince Gcorge's Hospital Center

Cheverly, MD 20785

Daniel Wohlgelernter, M.D., F.A.C.C.

Consulting Cardiologist

St. John's Hospital

Santa Monica, CA 90404 


\section{ACKNOWLEDGMENTS}

The effort and challenge involved in putting this book together was far greater than ever anticipated, and its completion was made possible by the excellent work of my highly talented contributors. I am especially indebted for their very timely submission of state-of-the-art manuscripts.

I would like to offer my deepest appreciation to my friend and colleague, Dr. Michael J. Domanski, without whose help this volume would not have been possible. A special acknowledgement must be reserved for Mrs. Grace Murtagh, for her extraordinary secretarial support. I am decply appreciative of my associates, Dr. Marc H. Wish, Dr. Tomas Hernandez, and Dr. Sudhakar Punja, for their profound support. I would also like to thank my cath lab personncl for helping $\mathrm{mc}$ to develop the percutaneous technique for the institution of cardiopulmonary bypass support.

I am deeply grateful to my sons, David and Jonathan, for their understanding of the time necessary to make this book a reality. Finally, I would like to offer special thanks to Mr. Jeffrey Smith, Director of Kluwer Academic Publishers, for the publication of this volume.

Fayaz A. Shawl, M.D. 


\section{FOREWORD}

Interventional cardiology is a creative, innovative, and rapidly advancing frontier of cardiology. There has been mind-boggling proliferation of technology in this field, the use of which requires extraordinary skills and knowhow. In order to keep pace with the innovative genius of interventional cardiologists, it is indeed desirable to have specialty issues updating us on technology-orientated therapeutic procedures.

Contemporary interventional cardiology care is a highly specialized art, dependent on critical decision making, selection of the most appropriate interventional procedure, and the operator possessing extraordinary skills and compassion.

This first volume of the new series, Supported Complex and High Risk Coronary Angioplasty, attests to the preceding statement. Dr. Fayaz Shawl has mastered the procedure and has been very thoughtful and innovative in the clinical application of the percutaneous cardiopulmonary bypass support technique. This book provides to an interventionist the basic principles of cardiopulmonary bypass, identification of the high risk coronary angioplasty patient, and other alternate support devices for myocardial protection. Dr. Shawl and his team of talented contributors are to be complimented for providing us with this impressive volume on high technology.

There will be ongoing specialty issues in this series highlighting the developments, complications, and advances in interventional cardiology. 


\section{PREFACE}

The practice of cardiology has changed dramatically since the introduction of percutaneous transluminal coronary angioplasty. The indications for coronary angioplasty are cvolving from the classical single-vessel proximal, concentric, noncalcified subtotal obstruction to the very high risk patients, including those deemed inoperable. The evolving changes reflect the expanding horizons in the technology-oriented therapeutic alternatives and the blossoming of innovative, sophisticated technologies. Catheter-based interventional cardiology has gained widespread acceptance and its applications in a significant number of patients attests to its safety and feasibility. It appears the balloon and the wire can tackle any anatomic lesions or location, but can cause hemodynamic collapse if coronary angioplasty is performed in high risk patients. Such patients generally have severely depressed left ventricular function and/or only one remaining patent vessel or a target vessel that supplies greater than one half of the remaining viable myocardium. In such cases, an abrupt closure may spell hemodynamic crisis with imminent death.

To make the procedure safe and fessible, and to reduce the prohibitive risk of the procedure, an innovative technology has emerged from the operating room. This is the development of percutancous cardiopulmonary bypass support (PCPS), which can circumvent the potential problems of the high risk procedure, provide hemodynamic support, and facilitate emergency coronary angioplasty, even in the most high risk patients. In addition, early institution of PCPS can stabilize patients who suffer cardiac arrest in the catheterization 
xviii Preface

laboratory, as well as facilitate coronary angioplasty or transfer to the operating room for coronary bypass graft surgery.

This is a specialized procedure and hence this book is intended to provide detailed information on all aspects of the procedure and potential procedurerelated risks and complications. I must caution that decisions about the selection of complex cases and the strategy for the complete procedure should be made in concert with the referring physician, cardiac surgical team, and interventional team. Analysis of many complex factors must be taken into account before embarking on this path of salvaging myocardium and life.

The complete procedure, which includes insertion and operation of PCPS, performance of coronary angioplasty, and termination of bypass, is indeed a complex and multifaceted technique. Extraordinary skills and well-thoughtout management strategy will enhance the success and safety of the procedure. The basic priniciples of cardiopulmonary bypass physiology will be discussed, and an approach to supported angioplasty in high risk patients will be developed. The results of cardiopulmonary bypass supported interventions will be discussed.

This book also attempts to describe the most up-to-date technology of various other support devices, which may be beneficial in supporting certain subgroups of patients undergoing high risk coronary intervention. Present prospects and future developments will be explored with an innovative bend.

Fayaz A. Shawl Editor 